\title{
Long non-coding RNA MIAT promotes papillary thyroid cancer progression through upregulating LASP1
}

Wei Liu ${ }^{\dagger}$, Zhenglin Wang ${ }^{\dagger}$, Cong Wang and Zhilong Ai*

\begin{abstract}
Background: Accumulating evidences indicate that long non-coding RNAs (IncRNAs) play an important role in initiation and development of thyroid cancer. However, the underlying molecular mechanism remains elusive.

Methods: To explore potential oncogenic and tumor suppressive IncRNAs in papillary thyroid cancer (PTC), we performed RNA sequencing to discover differentially expression IncRNAs between PTC tissues and matched normal tissues. RT-qPCR was used to validate differentially expressed IncRNAs. Bioinformatic analysis was performed to predicted potential miRNA and gene which might be regulated by MIAT. Cell proliferation, invasion and cycle assay were conducted to study the function of MIAT and LASP1 in PTC.

Results: Through analysis of RNA sequencing, we observed that IncRNA-MIAT was overexpressed in PTC tissues. The upregulation of MIAT was further confirmed in 40 pairs of PTC tissues and normal tissues we collected. In the function assays, results suggested that MIAT silencing led to inhibition of cell proliferation, invasion and disruption of cell cycle progression in PTC cells. Mechanistically, MIAT directly bound to miR-324-3p and upregulated LASP1 expression in PTC cells. In addition, expression of MIAT was positively correlated with LASP1 mRNA expression in samples collected from patients with PTC. More importantly, transfection of recombinant LASP1 attenuated MIAT silencing induced inhibition of cell proliferation, invasion and disruption of cell cycle progression in PTC cells.
\end{abstract}

Conclusions: In conclusion, the findings suggest that IncRNA-MIAT may promote PTC proliferation and invasion through physically binding miR-324-3p and upregulation of LASP1.

Keywords: MIAT, Papillary thyroid cancer, miR-324-3p, LASP1, Proliferation

\section{Background}

Globally, thyroid cancer is the most commonly diagnosed endocrine malignancy, accounting for nearly $5 \%$ of new cancer cases [1]. Papillary thyroid cancer (PTC) is the most common type of thyroid cancer [2]. Patients with PTC have an excellent prognosis and more than half of the patients are curable [3]. However, there are still 30\% of patients with aggressive PTC develop recurrence and distant metastasis, which would lead to patient death [4]. It is urgent to discover molecular mechanism of PTC to

\footnotetext{
*Correspondence: ai.zhilong@zs-hospital.sh.cn

†Wei Liu and Zhenglin Wang contributed equally to this work

Department of General Surgery, Zhongshan Hospital, Fudan University, 180 Fenglin Road, Shanghai 200032, China
}

develop new effective therapeutic approaches so as to fulfil clinical needs.

Long non-coding RNAs (lncRNAs) are a class of transcripts with more than 200 nucleotides in length that are not translated into protein [5]. In recent years, studies reveal that a majority of lncRNAs are pivotal regulators of normal physiology processes [6, 7]. Dysregulation of IncRNAs are observed in many human diseases and contribute to disease progression [8-11]. Several lncRNAs were proved to play an important role during thyroid cancer carcinogenesis [12]. For example, lncRNA ANRIL inactivated TGF- $\beta /$ Smad signaling pathway to reduce p15INK4B expression in thyroid cancer cells, led to enhanced cell invasion and metastasis ability [13]. LncRNA myocardial infarction associated transcript

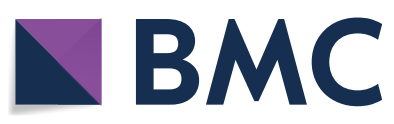

(c) The Author(s) 2019. This article is distributed under the terms of the Creative Commons Attribution 4.0 International License (http://creativecommons.org/licenses/by/4.0/), which permits unrestricted use, distribution, and reproduction in any medium, provided you give appropriate credit to the original author(s) and the source, provide a link to the Creative Commons license, and indicate if changes were made. The Creative Commons Public Domain Dedication waiver (http://creativecommons.org/ publicdomain/zero/1.0/) applies to the data made available in this article, unless otherwise stated. 
(MIAT) was firstly identified to be associated with a susceptibility to myocardial infarction [14]. Later, overexpression of MIAT was discovered in several types of cancers including neuroendocrine prostate cancer, breast cancer and chronic lymphocytic leukemias [15-17]. Mechanistically, previous studies showed that MIAT acted as a competing endogenous RNA (ceRNA) to physically bind miRNA and regulated gene expression [18]. However, it is still unknown whether and how MIAT contributes to PTC progression.

LIM and SH3 domain protein 1 (LASP1) is a member of LIM protein family which contains a LIM domain and two actin-binding domains [19]. In cells, LASP1 interacts with actin cytoskeleton and was reported to localized within sites of actin assembly [20]. In normal tissues, LASP1 is ubiquitously expressed and highly expressed in actin-rich tissues types [21]. In human tumor tissues, LASP1 is significantly overexpressed and plays a pivotal role for cancer aggressiveness [22]. The function assays suggested that LASP1 was involved in cell proliferation, migration and cycle regulation in cancer cells [23]. Most recently, a study showed that LASP1 was overexpressed in thyroid cancer and contributed to strong cell proliferation and migration ability of thyroid cancer cells through activation of PI3K/AKT pathway [24].

In this study, we discovered several differentially expressed lncRNAs between PTC tissues and normal tissues using RNA sequencing. We identified and confirmed MIAT as an upregulated lncRNA in PTC tissues compared with normal tissues. In the functional assays, our results showed that MIAT silencing decreased cell proliferation and invasion ability, disrupted cell cycle progression of PTC cells. Bioinformatic analysis and RTqPCR defined a MIAT/miR-324-3p/LASP1 axis in PTC cells. The direct interaction among MIAT, miR-324-3p and LASP1 was verified with the dual luciferase reporter assay. Furthermore, rescue experiments suggested that MIAT regulated PTC cell proliferation, invasion and cycle rely on regulation of LASP1. These data demonstrated that MIAT might be a key lncRNA in promoting PTC progression.

\section{Materials and methods}

\section{Collection of patient samples}

A total of 40 pairs of PTC tissues and matched normal tissues were collected from patients who underwent surgical resection at Zhongshan Hospital, Fudan University during June 2015 to September 2017. No patients received chemotherapy or radiotherapy before surgery. The diagnosis of PTC was histopathological confirmed. All experiments were supervised by the Ethic Committee of Fudan University. Written consent was obtained from all participants before the study. The tissues were immediately frozen in liquid nitrogen then stored in $-80^{\circ} \mathrm{C}$ for the following RNA extraction.

RNA extraction, sequencing and expression quantification RNA was extracted from 3 pairs of tissue samples using the Qiagen AllPrep DNA/RNA/Protein mini kit (Qiagen, Valencia, CA) according to the manufacturer's protocol. After total RNA was extracted, rRNAs were removed to retain mRNAs and ncRNAs. The enriched mRNAs and ncRNAs were fragmented into short fragments by using fragmentation buffer and reverse transcribed into cDNA with random primers. Second-strand cDNA were synthesized by DNA polymerase I, RNase H, dNTP (dUTP instead of dTTP) and buffer. Next, the cDNA fragments were purified with QiaQuick PCR extraction kit (Qiagen), end repaired, poly(A) added, and ligated to Illumina sequencing adapters. Then UNG (Uracil- $N$-Glycosylase) was used to digest the second-strand cDNA. The digested products were size selected by agarose gel electrophoresis, PCR amplified, and sequenced using Illumina HiSeqTM 4000 by Gene Denovo Biotechnology Co. (Guangzhou, China). The reads of each sample were then mapped to reference genome by TopHat2 (version 2.1.1) and expression quantification was achieved using software RSEM [25]. We identified transcripts with a fold change $\geq 2$ and a false discovery rate $(F D R)<0.05$ in a comparison as significant DEGs.

\section{Cell culture}

Papillary thyroid cancer cell lines HTH83 and BHT101 were bought from Cell Bank, Chinese Academy of Sciences (Shanghai, China). All cell lines were cultured in DMEM medium (Gibco, Rockville, MD) containing 10\% FBS (Gibco) in a $37^{\circ} \mathrm{C}$ incubator with $5 \% \mathrm{CO}_{2}$.

\section{Bioinformatic analysis}

The expression of lncRNAs in 9 pairs of papillary thyroid cancer tumor tissues and matched normal tissues from GSE3467 were downloaded from GEO database (https ://www.ncbi.nlm.nih.gov/geo/). The expression of MIAT was analyzed using GEO2R online software. Expression data of MIAT and LASP1 in TCGA dataset (cell, 2014, containing expression data of 486 patients with PTC) were downloaded using cBioPortal [26]. The prediction of potential miRNA-mRNA interaction was carried out on miRDB V.5.0 (http://mirdb.org/). The expression of miR-324-3p and MIAT in 509 papillary thyroid cancer tissues from TCGA (The Cancer Genome Atlas) were analyzed on Starbase V.3.0 database (http://starbase.sysu. edu.cn/). 


\section{RNA extraction and RT-qPCR}

Total RNA was extracted from tissues and cells using TRIzol reagent (Invitrogen, Carlsbad, CA) following manufacturer's protocol. The RNA was reverse transcribed into first stranded cDNA using ReverTra Ace- $\alpha$ qPCR RT Kit (Toyobo, Osaka, Japan). The qPCR was performed using SYBR Green Master Mix (Roche, Basel, Switzerland) on a CFX96 system (Bio-Rad, Hercules, CA). GAPDH and U6 were used as internal controls for mRNA and miRNA respectively. The relative expression of gene was calculated using $2^{-\Delta \Delta C T}$ [27]. The primer sequences were listed in Table 1.

\section{Protein extraction and western blotting}

Protein lysates were prepared using RIPA lysis buffer (Beyotime, Shanghai, China). Antibodies against LASP1 (\#8636, 1:1000) and GAPDH (\#5174, 1:10,000) were purchased from Cell Signaling Technology (Lane Danvers, MA). Secondary antibodies for rabbit (\#ab7090, 1:10,000) and mouse (\#ab97040, 1:10,000) were obtained from Abcam (Cambridge, UK). $20 \mu \mathrm{g}$ protein lysates were loaded into each lane on the 8\% SDS-PAGE gel and then transferred into a PVDF membrane. The membrane was incubated with indicated primary antibody at $4{ }^{\circ} \mathrm{C}$ overnight. On the next day, the membrane was incubated

\section{Table 1 Sequence of primers}

\begin{tabular}{ll}
\hline Primer & Sequence \\
\hline MIAT-F & 5'-GCACCTTGAGTGAATGTCAAGGCAG-3' \\
MIAT-R & 5'-TGGCAGCATCCAGCCGACACACAGG-3' \\
LASP1-F & 5'-TGCGGCAAGATCGTGTATCC-3' \\
LASP1-R & 5'-GCAGTAGGGCTTCTTCTCGTAG-3' \\
COLCA1-F & 5'-CTTATGACAGGAAAGTGGAAG-3' \\
COLCA1-R & 5'-TAGCATCAAGTTCCCATCCAC-3' \\
SHNG14-F & 5'-TGCACAAAATAAGCCTGGCTGT-3' \\
SHNG14-R & 5'-TCAATATTTAATACAGGCATGCA-3' \\
SHNG15-F & 5'-TTCAGACAATGACTTCCTCCCTCCT-3' \\
SHNG15-R & 5'-TAGCTCCTGGGGCACTCAGCTC-3' \\
RNU12-F & 5'-TGCCTTAAACTTATGAGTAAGG-3' \\
RNU12-R & 5'-GGGCCGGACTTATCTTTCTGAA-3' \\
LINC00667-F & 5'-CTGAAATCACAGCAATGCCAGTTT-3' \\
LINC00667-R & 5'-TATAGCTTTGATTTCTTGCAGTGT-3' \\
GAPDH-F & 5'-TTTGGTCGTATTGGGCGCCTGGTCA-3' \\
GAPDH-R & 5'-TTGTGCTCTTGCTGGGGCTGGTGGT-3' \\
Stem-loop & 5'-CTCAACTGGTGTCGTGGAGTCGGCAAT \\
miR-324-3p-F & TCAGTTGAGCCAGCA-3' \\
miR-324-3p-R & 5'-GCCGAGCCCACTGCCCCAGG-3' \\
U6-F & 5'-CTCAACTGGTGTCGTGGA-3' \\
U6-R & 5'-CTCGCTTCGGCAGCACA-3' \\
\hline
\end{tabular}

with secondary antibody at room temperature for $1 \mathrm{~h}$. The blot was developed with ECL Western Blotting Substrate (Pierce; Thermo Fisher Scientific, Waltham, MA).

\section{Silencing of MIAT}

Control siRNA, MIAT siRNA1 and MIAT siRNA2 were synthesized and purchased from GenePharma (Shanghai, China). The sequences were: control siRNA:5'-UUCUCC GAACGUGUCACGUTT-3'; MIAT siRNA1:5'-GGU GUUAAGACUUGGUUUCTT-3'; MIAT siRNA2:5'ACUUCUUCGUAUGUUCGGCTT- ${ }^{\prime}$ '. For silencing of MIAT, MIAT siRNA1 or MIAT siRNA2 were mixed with Lipofectamine RNAiMax (Invitrogen) in $500 \mu \mathrm{L}$ serumfree medium for $5 \mathrm{~min}$, then added into culture medium. After $48 \mathrm{~h}$, the cells were harvested and subjected to the following experiments.

\section{Overexpression and downregulation of miR-324-3p}

MiR-NC mimic, miR-324-3p mimic, miR-NC inhibitor and miR-324-3p inhibitor were bought from GenePharma (Shanghai, China). MiRNA mimic or miRNA inhibitor was transfected into indicated cells using Lipofectamine RNAiMax (Invitrogen). After $48 \mathrm{~h}$, the cells were harvested and subjected to the following experiments.

\section{Construction of plasmid and overexpression of LASP1}

Full length of LASP1 open reading frame was amplified from HTH83 cDNA and ligated into pcDNA3. For overexpression of LASP1, pcDNA3-LASP1 plasmids were mixed with Lipofectamine 3000 (Invitrogen) in $500 \mu \mathrm{L}$ serum-free DMEM medium for $15 \mathrm{~min}$, then added into culture DMEM medium. After $48 \mathrm{~h}$, the cells were harvested and subjected to the following experiments.

\section{Dual luciferase reporter assay}

The 3'UTR of LASP1 was amplified from HTH83 cDNA and ligated into pGL3 plasmid. QuickChange Sitedirected Mutagenesis Kit (Agilent Technologies, Santa Clara, CA) was used to introduce site mutations into LASP1 3'UTR-WT. For the dual luciferase reporter assay, cells were transfected with LASP1 $3^{\prime}$ UTR-WT or LASP1 $3^{\prime}$ UTR-Mut in combination with miR-NC mimic or miR324-3p mimic using Lipofectamine 3000 (Invitrogen). After $48 \mathrm{~h}$, the relative luciferase activity of each well was determined using Dual Luciferase Reporter System (Promega, Madison, WI).

\section{Cell invasion assay}

Cell invasion assays were carried out using modified Boyden chambers consisting of Transwell (Corning Costar Corp., Cambridge, MA) membrane filter inserts in 24-well plates. The Transwell filters were $8 \mathrm{~mm}$ pore size 
polycarbonate membranes. The upper surfaces of the Transwell membranes were pre-coated with $1 \mathrm{mg} / \mathrm{mL}$ Matrigel (Becton-Dickinson Labware, Franklin Lakes, $\mathrm{NJ})$ overnight at $4{ }^{\circ} \mathrm{C}$ then placed into 24-well plates. In each well, $500 \mu \mathrm{L}$ culture medium was added. Cells $\left(2 \times 10^{5}\right)$ in $100 \mu \mathrm{L}$ of serum-free medium were added to each Transwell chamber and allowed to invade toward the underside of the membrane for $24 \mathrm{~h}$. Cells in the upside of the chamber were removed, and the invaded cells were fixed and stained using $0.4 \%$ Crystal Violet Staining Solution (Solarbio, Beijing, China). The number of invaded cells per membrane was counted under a light microscope.

\section{Cell proliferation assay}

The proliferation ability of cells was detected using Cell Counting Kit-8 (DoJinDo, Kumamoto, Japan) according to the manufacturer's protocol. 1000 cells were seeded in each well in the 96-well plates. On the next day, cells were transfected with siRNA with or without plasmids. At the time point of $0,24,48,72 \mathrm{~h}$ after treatment, $10 \mu \mathrm{L}$ CCK- 8 solution was added into each well and maintained for $1 \mathrm{~h}$. The medium containing CCK- 8 was then transferred into wells in a new 96-well plate and the absorbance at $450 \mathrm{~nm}$ was detected by a Microplate Reader (Bio-Rad) to reflect cell proliferation ability.

\section{Cell cycle assay}

For cell cycle analysis, the cells were stained with Propidium Iodide (PI, Invitrogen). Briefly, after treatment, the cells were collected, washed with PBS and then fixed in $70 \%$ ethanol at $4{ }^{\circ} \mathrm{C}$ overnight. After that, PI was added into cell suspension and sustained for $30 \mathrm{~min}$, after that, the cell distribution was analyzed on a flow cytometry (Becton-Dickinson Labware) with FlowJo software (Version 6.3.1, Tree Star Inc., Ashland, OH).

\section{Statistical analysis}

All data analysis was carried out using Graphpad Prism 6.0 software. The values were presented as the mean \pm SD. Differences between two groups were analyzed using Student's t test. Differences from multiple groups were firstly analyzed with one-way ANOVA followed by Newman-Keuls analysis. A p value less than 0.05 was considered statistically significant.

\section{Results}

MIAT is highly expressed in papillary thyroid cancer (PTC) tissues and cells

Using RNA sequencing method, we compared the expression of lncRNAs in three pairs of PTC tissues and normal tissues. The bioinformatic analysis revealed that several lncRNAs were differentially expressed (8 upregulated lncRNAs and 23 downregulated lncRNAs) between PTC tissues and normal tissues (Fig. 1a, b). Among them, most recent studies revealed that lncRNAs such as TNRC6C-AS1 were associated with progression of PTC $[28,29]$. A total of 6 differentially expressed lncRNAs (COLCA1, MIAT, SNHG14, RNU12, SNHG15, LINC00667) were selected for validation in 10 pairs of PTC tissues and normal tissues using RT-qPCR. The data showed that these lncRNAs were differentially expressed between examined PTC tissues and normal tissues, and MIAT was significantly upregulated in PTC tissues (Fig. 1c). For further evaluation of our discovered differentially expressed lncRNAs in PTC, the array data in 9 pairs of PTC tissues and normal tissues were downloaded from GSE3467. The analysis indicated that TNRC6C-AS1 and MIAT expression were consistently increased in PTC tissues and MIAT was the most significantly upregulated lncRNA (Fig. 2a, Additional file 1: Figure S1). Moreover, in 40 pairs of PTC tissues and normal tissues we collected, overexpression of MIAT were also observed in PTC tissues (Fig. 2b). Additionally, it was observed that MIAT expression was significantly upregulated in HTH83 and BHT101, two PTC cell lines, compared with two normal thyroid tissues from patients with PTC (Fig. 2c). The data suggested that MIAT might promote PTC progression.

\section{MIAT promotes cell proliferation, cell cycle progression and invasion in PTC cells}

To investigate the role of MIAT in PTC, MIAT was downregulated by transfection of two MIAT siRNAs in HTH83 and BHT101. Transfection of MIAT siRNA significantly downregulated MIAT expression in HTH83 and BHT101 cells (Fig. 3a). The cell proliferation assay data suggested that silencing of MIAT significantly inhibited the proliferation ability of both cell lines (Fig. 3b, c). Through the cell cycle analysis, we observed that MIAT downregulation increased cells accumulated in G2/M phase in HTH83 (Fig. 3d, e). Similar results were detected in BHT101 (Fig. 3f, g). In addition, it was found that the invasion capacity of HTH83 and BHT101 cells was greatly limited towards MIAT silencing (Fig. $3 \mathrm{~h}$, i). These results collectively manifested that MIAT was pivotal for proliferation and metastasis of PTC cells.

\section{MIAT acts as a competitive endogenous RNA (ceRNA) and directly binds to miR-324-3p in PTC cells}

Using Starbase V.3.0 database, we predicted several potential miRNAs which might bind to MIAT. Among them, miR-324-3p harbors a potential binding site for MIAT (Fig. 4a) and its expression is negatively correlated $(\mathrm{r}=-0.365, \mathrm{p}<0.000)$ with MIAT levels in expression data of 509 thyroid carcinoma tissues (THCA) from 

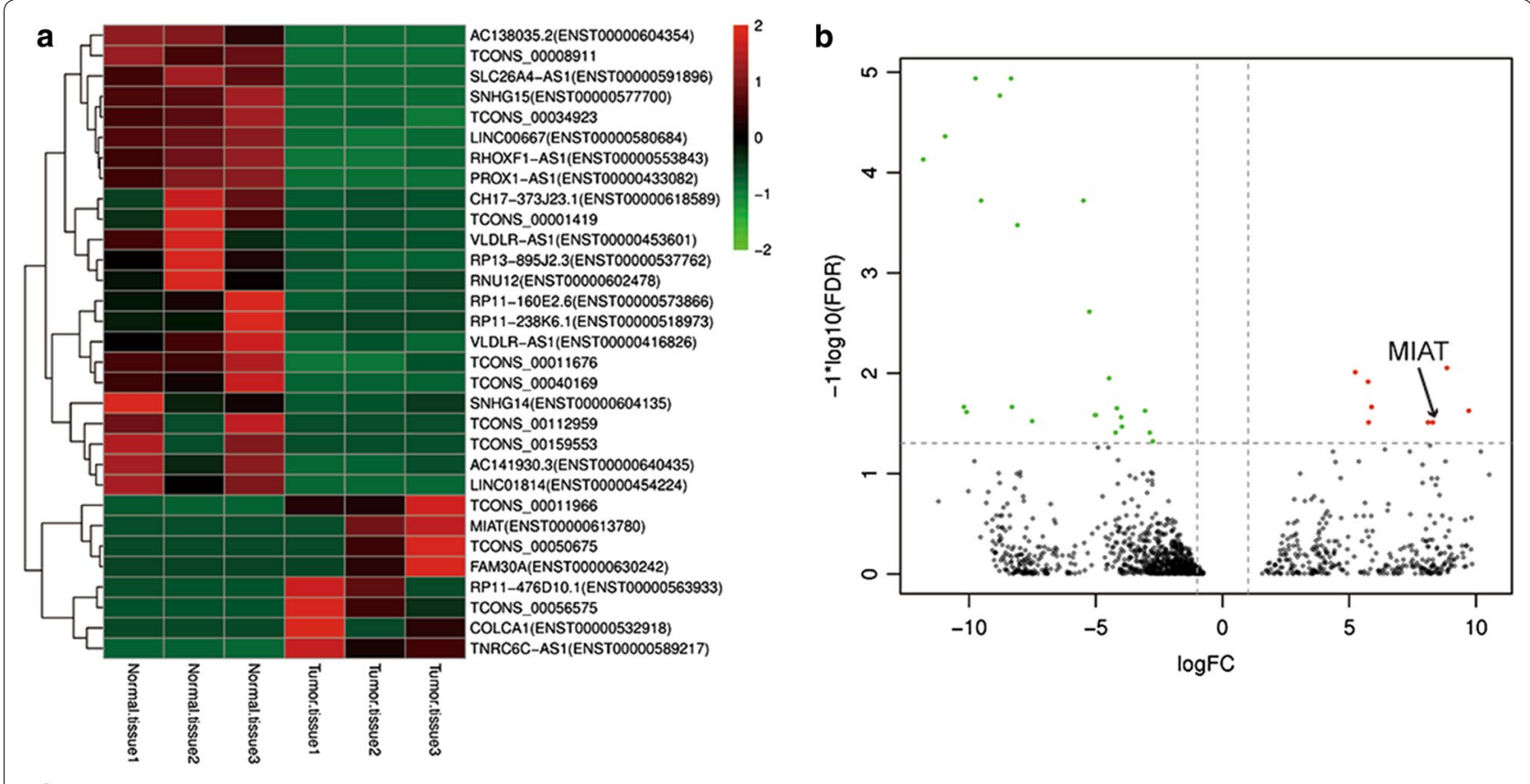

C

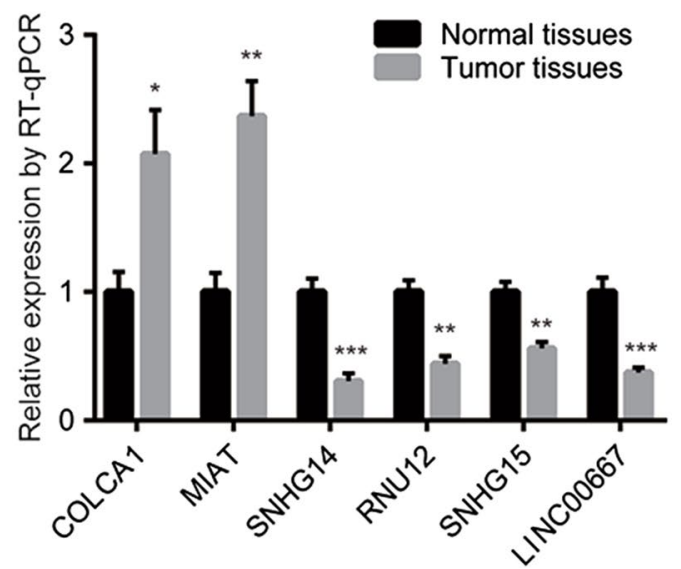

Fig. 1 Screen of differentially expressed IncRNAs in papillary thyroid cancer. a Heatmap of differentially expressed IncRNAs (8 upregulated and 23 downregulated) in 3 papillary thyroid cancer tissues compared with matched normal tissues. b Volcano plots were constructed based on sequencing results of differentially expressed IncRNAs between papillary thyroid cancer tissues and normal tissues from 3 patients. The red points represent differentially upregulated genes, and green points represent downregulated genes. Arrow indicated MIAT in the plots. c RT-qPCR was performed to validate 6 differentially expressed IncRNAs ( 2 upregulated and 4 downregulated) obtained from sequencing of papillary thyroid cancer tissues and normal tissues of 3 patients. ${ }^{*} p<0.05 ;{ }^{* *} p<0.01 ;{ }^{* * *} p<0.001$

TCGA (Fig. 4b). In the dual luciferase assay, overexpression of miR-324-3p significantly reduced relative luciferase activity of MIAT-WT in both HTH83 and BHT101 cells while the relative luciferase activity of MIAT-MUT (with two site mutations in potential binding sequence) was not altered in both cell lines (Fig. 4c-e). Overexpression of miR-324-3p downregulated MIAT expression in HTH83 and BHT101 cells (Fig. 4f). Conversely, MIAT silencing increased miR-324-3p levels in these two cell lines (Fig. 4g).

\section{MIAT regulates LASP1 expression via sponging miR-324-3p in PTC cells}

Using miRDB database, LASP1 was predicted to be a potential target gene of miR-324-3p (Fig. 5a). Overexpression of miR-324-3p reduced relative luciferase activity of LASP1 3'UTR-WT not LASP1 3'UTR-MUT (with two site mutations in potential binding sequence) in HTH83 and BHT101 cells (Fig. 5b, c). In both HTH83 and BHT101, transfection of miR-324-3p inhibitor increased LASP1 mRNA levels (Fig. 5d, e). Western 

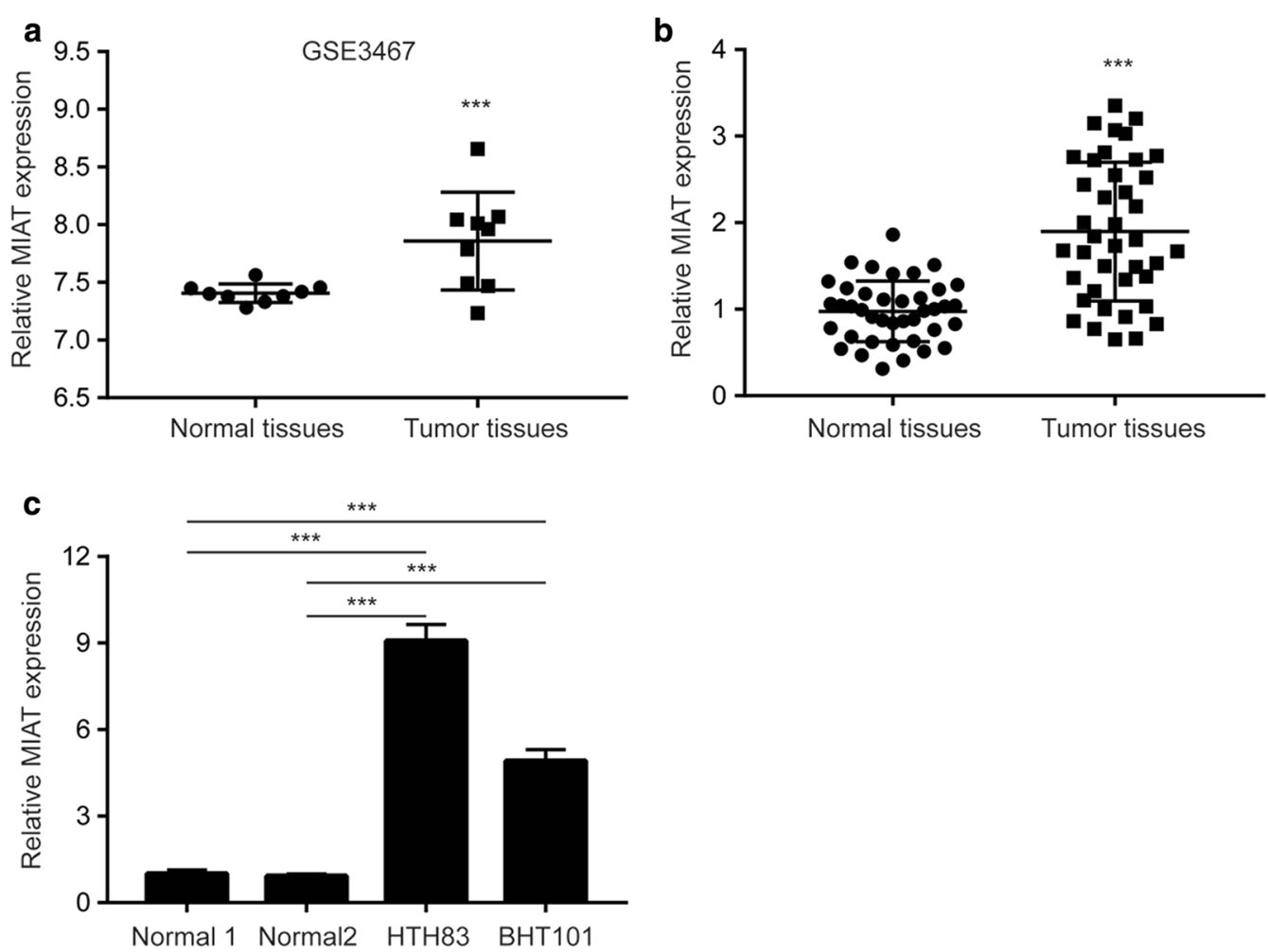

Fig. 2 MIAT is overexpressed in papillary thyroid cancer and cells. a Bioinformatic analysis of GSE3467 dataset revealed that MIAT was overexpressed in papillary thyroid cancer compared with normal tissues from 9 patients. b RT-qPCR showed that MIAT was overexpressed in papillary thyroid cancer compared with normal tissues from 40 patients enrolled in this study. c RT-qPCR showed that MIAT was overexpressed in HTH83 and BHT101 cells compared with two normal thyroid tissues from patients with papillary thyroid cancer. ${ }^{* * *} p<0.001$

blotting further showed that the protein levels of LASP1 was also increased towards miR-324-3p downregulation (Fig. 5f, g). More importantly, we found that silencing of MIAT decreased LASP1 protein levels which was reversed after co-transfection of miR-324-3p inhibitor in the two cell lines (Fig. 5h, i). The data suggested that MIAT, miR-324-3p and LASP1 acted together in a ceRNA mechanism.

\section{The MIAT/miR-324-3p/LASP1 axis determines the cell proliferation, cycle and invasion of PTC cells}

To investigate whether the new identified MIAT/miR324-3p/LASP1 axis was involved in development of PTC, we performed functional assays in cells transfected with MIAT siRNA in combination with recombinant LASP1. As showed in Fig. 6a, overexpression of LASP1 reversed MIAT downregulation induced cell growth arrest. In addition, LASP1 overexpression attenuated MIAT silencing induced cell accumulation at G2/M phase (Fig. 6b, c). Moreover, LASP1 overexpression also reversed reduced cell invasion ability led by MIAT silencing (Fig. 6d). The data collectively manifested that MIAT regulated PTC development via regulation of LASP1.
LASP1 expression is positively correlated with MIAT in PTC tissues

For further examine the clinical association between LASP1 and MIAT expression, expression data of 9 pairs of PTC tissues and normal tissues from GSE3467 was analyzed. As we expected, a positive correlation $(r=0.583, p<0.05)$ between their expression was observed (Fig. 7a). Furthermore, in a large cohort (TCGA, cell 2014), expression of MIAT was positively correlated with LASP1 levels in tumor from 486 patients with PTC $(r=0.292, p<0.0001)$ (Fig. $7 b)$. In the validation group (40 pairs of PTC tissues and normal tissues we collected), we also observed a positive correlation $(\mathrm{r}=0.524, \mathrm{p}<0.001)$ between LASP1 mRNA levels and MIAT levels (Fig. 7c).

\section{Discussion}

In PTC, several lncRNAs have already been identified as oncogenes or tumor suppressors through regulating key genes involved in cell proliferation and migration. In addition, some lncRNAs are proved to be excellent prognostic predictors for patients with PTC. In the present 

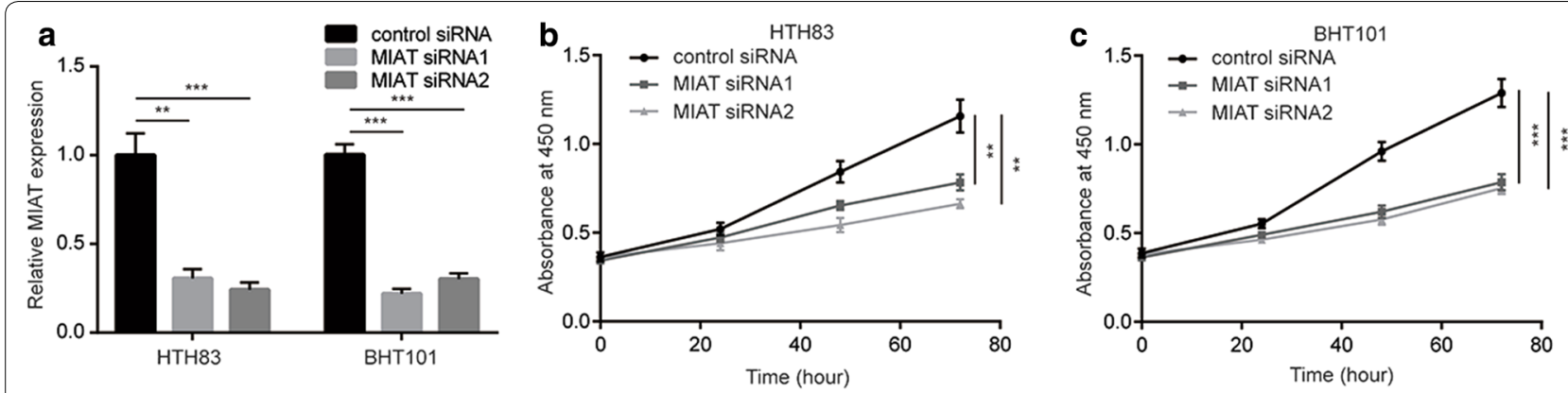

d
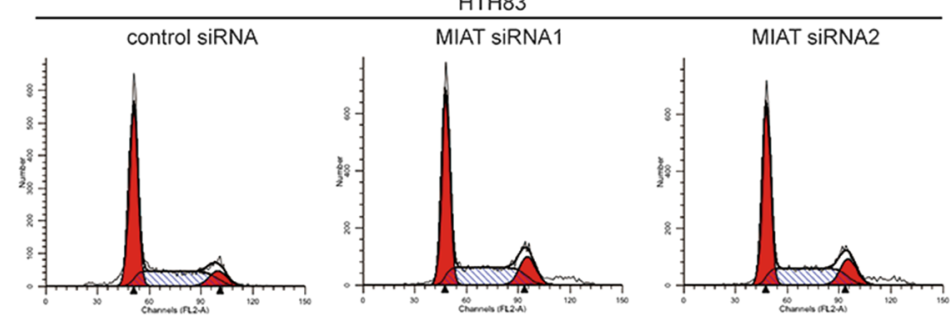

f

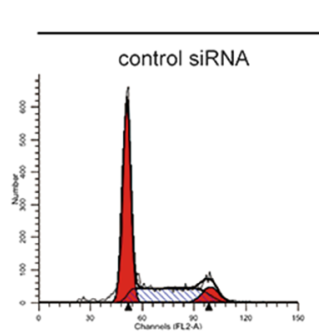

BHT101

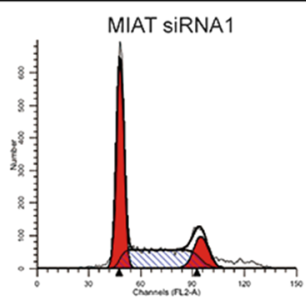

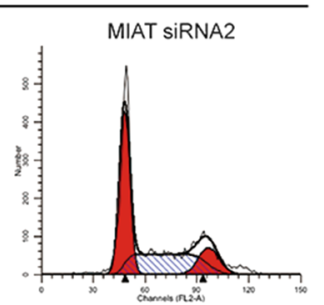

e
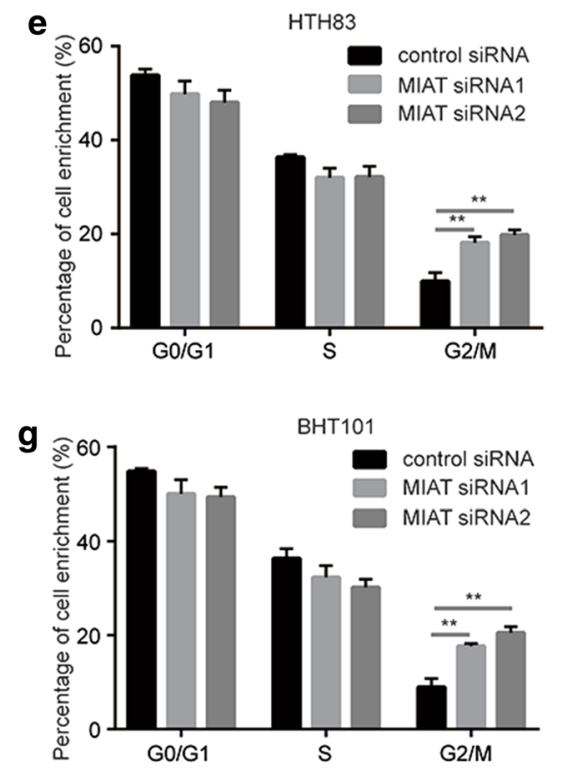

h

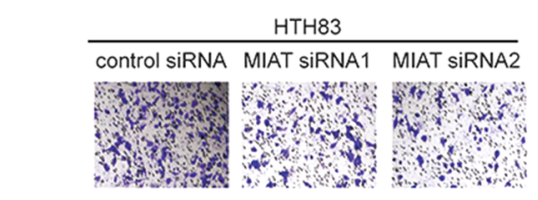

i
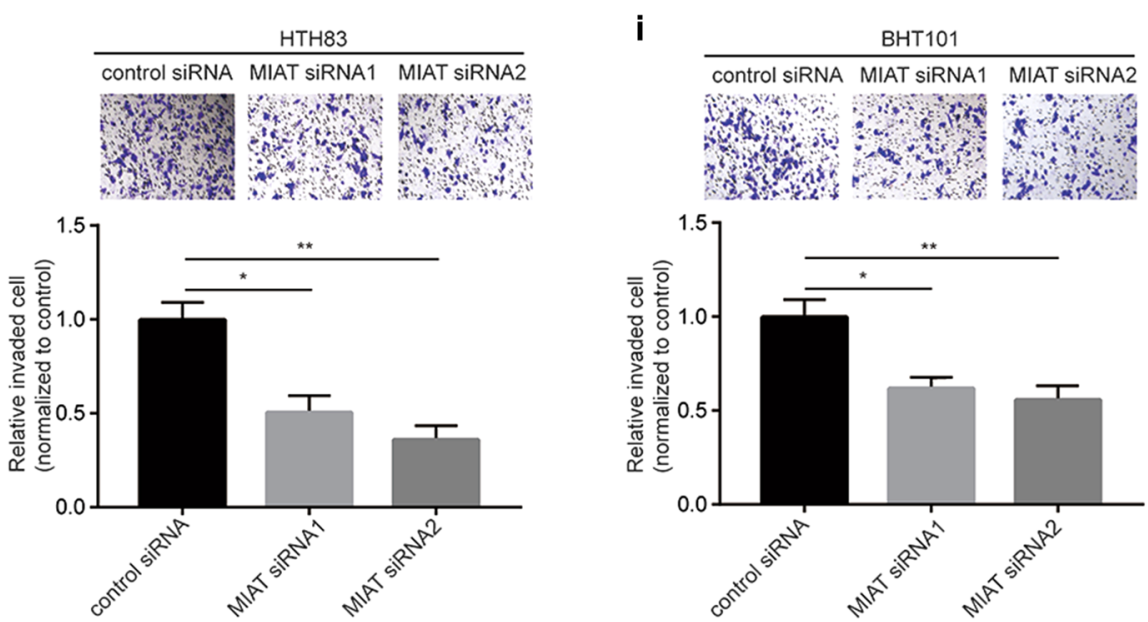

Fig. 3 Silencing of MIAT inhibits cell proliferation, cycle and invasion ability of papillary thyroid cancer cells. a Transfection of MIAT siRNA1 or MIAT siRNA2 reduced MIAT expression in HTH83 and BHT101 cells. $\mathbf{b}$ Silencing of MIAT inhibited cell proliferation of HTH83 cells in a cell proliferation assay. $\mathbf{c}$ Silencing of MIAT inhibited cell proliferation of BHT101 cells in a cell proliferation assay. $\mathbf{d}$ The cell cycle analysis showed that MIAT silencing induced accumulation of HTH83 cells in G2/M phase. e Quantitative analysis of HTH83 cells enriched in G1, S and G2/M phase in d. f The cell cycle analysis showed that MIAT silencing induced accumulation of BHT101 cells in G2/M phase. g Quantitative analysis of BHT101 cells enriched in G1, $\mathrm{S}$ and G2/M phase in $\mathbf{f}$. $\mathbf{h}$ Silencing of MIAT inhibited cell invasion of HTH83 cells in a cell invasion assay. $\mathbf{i}$ Silencing of MIAT inhibited cell invasion of BHT101 cells in a cell invasion assay. ${ }^{*} p<0.05 ;{ }^{* *} p<0.01 ;{ }^{* * *} p<0.001$ 
a

MIAT-WT 5' UUGGGAGUA-GAGGGGCAGG 3' hsa-324-3p 3' GgucGuCGUGGACCCCGUCA 5'

C
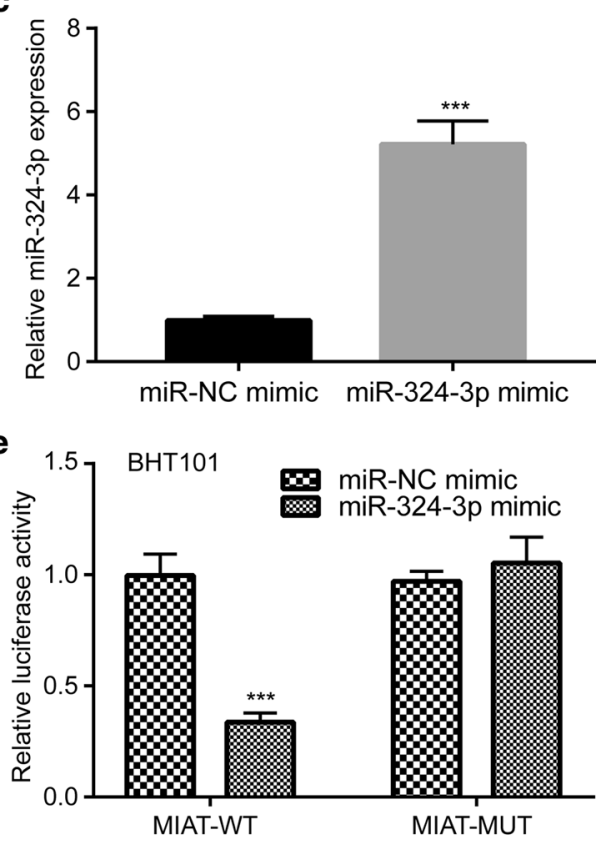

g

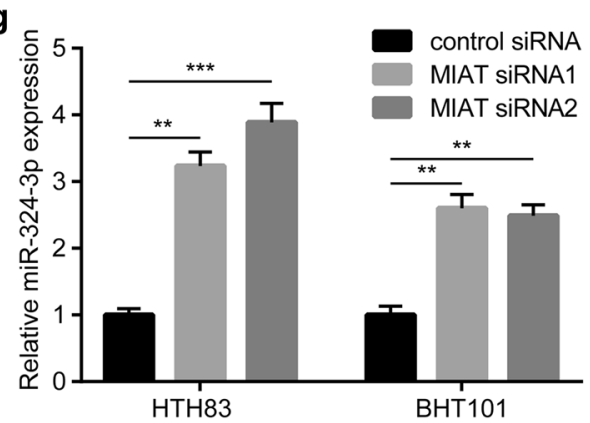

b

$4 \frac{509 \text { samples (THCA) }}{- \text { Regression }(y=-1.0560 x+3.0172)}$

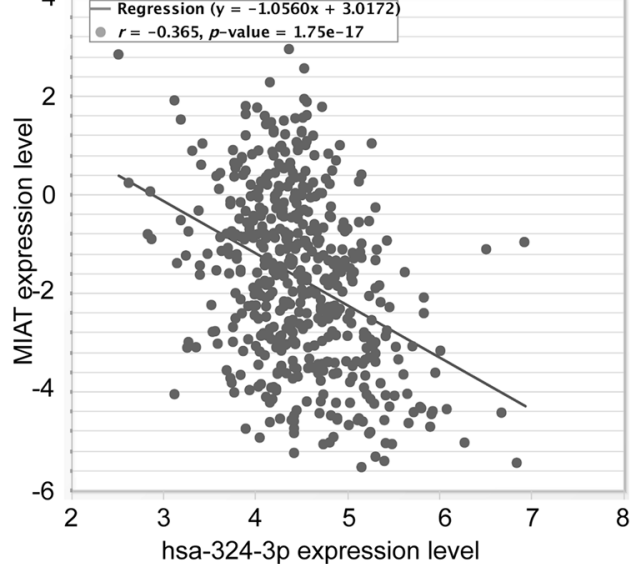

d

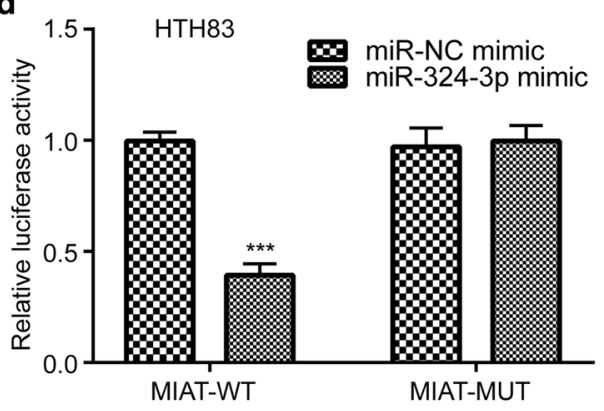

f

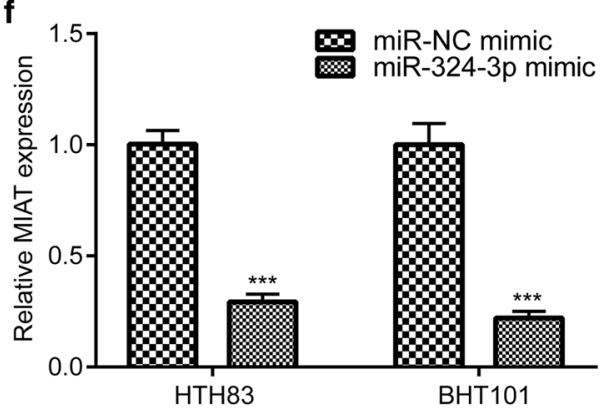

Fig. 4 MIAT directly binds miR-324-3p in papillary thyroid cancer cells. a Sequencing alignment showed that miR-324-3p harbored putative binding site for MIAT. b Through analysis of gene expression data in 509 papillary thyroid cancer tissues from TCGA, a negative correlation was observed between miR-324-3p levels and MIAT levels. c Transfection of miR-324-3p mimic increased miR-324-3p expression in HTH83 cells. $\mathbf{d}$ Overexpression of miR-324-3p reduced relative luciferase activity of MIAT-WT not MIAT-MUT in HTH83 cells. e Overexpression of miR-324-3p reduced relative luciferase activity of MIAT-WT not MIAT-MUT in BHT101 cells. $f$ Overexpression of miR-324-3p reduced miR-324-3p levels in HTH83 and BHT101 cells. g Silencing of MIAT increased miR-324-3p levels in HTH83 and BHT101 cells. ${ }^{* *} p<0.01 ;{ }^{* * *} p<0.001$ 


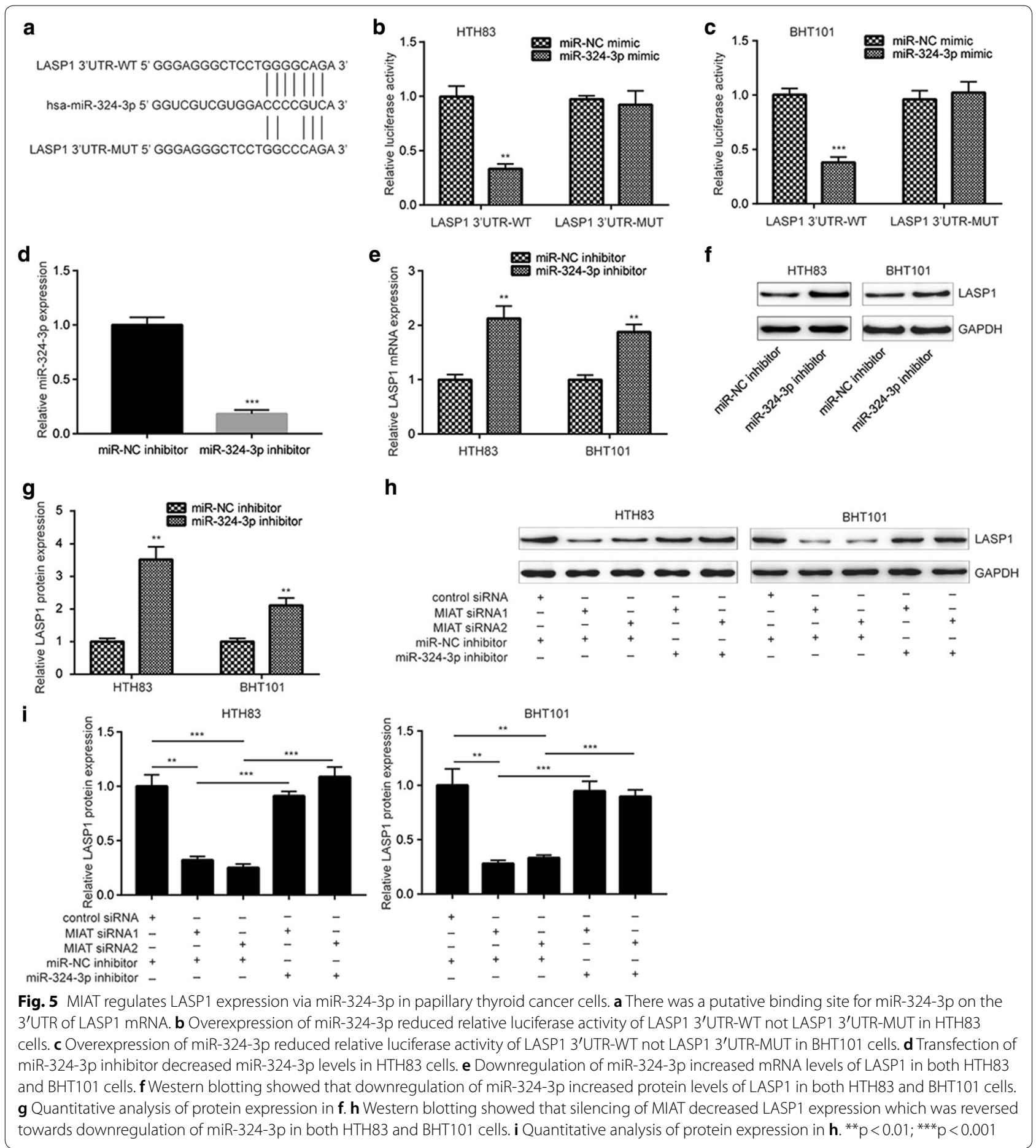

study, we firstly identified several differentially expressed lncRNAs between PTC tissues and normal tissue via sequencing. Among them, aberrant expression of SNHG14 and SNHG15 have been discovered in cancers [30, 31], expression of LINC00667 was proved as a biomarker to predict relapse free survival in patients with small hepatocellular carcinoma [32], most recently, the roles of VLDLR-AS1 and TNRC6C-AS1 in PTC have been studied [33, 34]. In the current study, we revealed a pivotal role of MIAT in regulation of PTC progression.

The overexpression of MIAT in tumor tissues has been reported in several cancer types [18, 35]. Using 

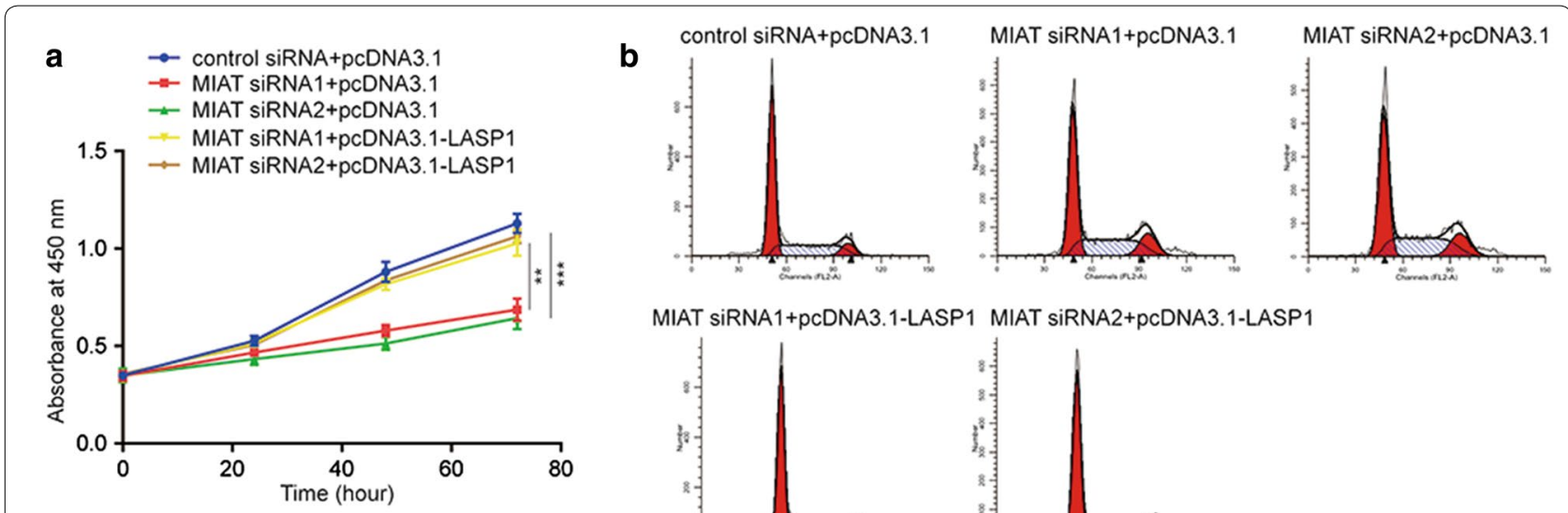

MIAT SIRNA1+pcDNA3.1-LASP1 MIAT siRNA2+pcDNA3.1-LASP1
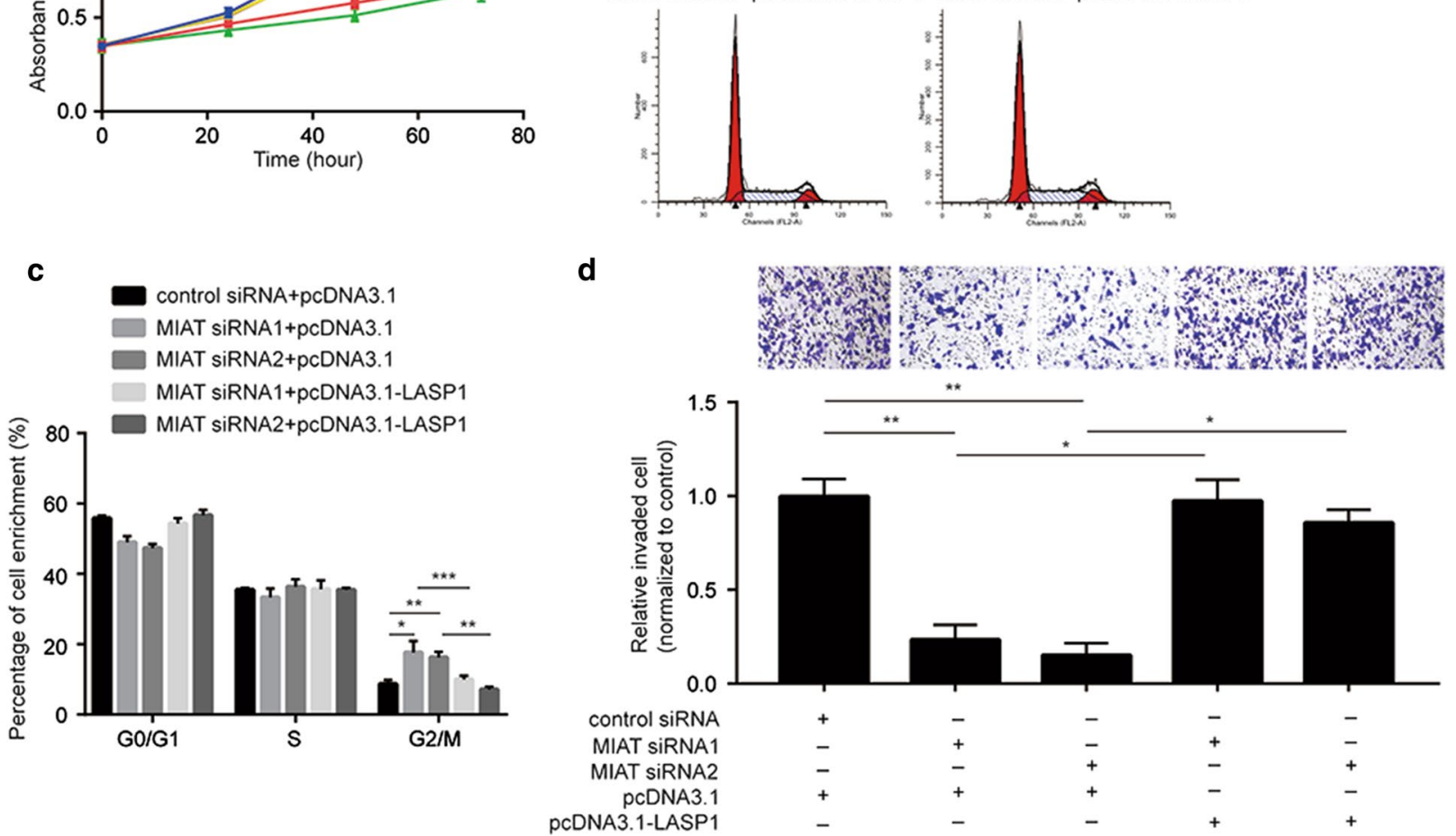

Fig. 6 Overexpression of LASP1 reverses MIAT silencing induced inhibition of cell proliferation, cycle and invasion in papillary thyroid cancer cells. a MIAT silencing inhibited cell proliferation which was reversed after transfection of recombinant LASP1 in HTH83. b MIAT silencing induced accumulation of cells in G2/M phase which was reversed after transfection of recombinant LASP1 in HTH83. c Quantitative analysis of cell cycle distribution in b. d MIAT silencing inhibited cell invasion ability which was reversed after transfection of recombinant LASP1 in HTH83. ${ }^{*} p<0.05$; ${ }^{* *} p<0.01$; ${ }^{* *} p<0.001$

RNA-seq method, we discovered that MIAT was one of the most significantly elevated lncRNAs in PTC tumor tissues compared with matched normal tissues. Functional assays suggested that MIAT played a key role in regulation of cell proliferation, invasion and cycle of PTC cells. Known as miRNA "sponge", competing endogenous RNAs (ceRNAs) are RNA transcripts that compete for binding to miRNA through the base-pairing method, which leads to reduction of miRNAs available to target mRNA [36]. Recent studies found that MIAT was involved in cancer progression via sponging miRNAs [37]. For example, in colorectal cancer cells, MIAT bound to miR-132, a tumor suppressor in colorectal cancer, led to downregulation of miR-132 and facilitate proliferation and metastasis of cancer cells [38]. Through bioinformatic analysis, we observed that MIAT might bind to miR-324-3p. MiR-324-3p was reported to be a tumor suppressor in nasopharyngeal carcinoma [39]. Moreover, the downregulation of miR-324-3p was discovered in many cancer types [40]. Our data showed that miR-324-3p was directly targeted by MIAT, suggested that MIAT might promote cancer progression via miR-324-3p.

LASP1 was a recently discovered oncogene in PTC [24]. Silencing of LASP1 inactivated PI3 K/AKT signaling and induced cell proliferation and migration inhibition in PTC cells [24]. Previous studies manifested that dysregulation of microRNAs led to LASP1 overexpression in cancer cells [41, 42]. In gastric cancer, hypermethylation of DNA led to downregulation of miR-29b, 


\section{a}

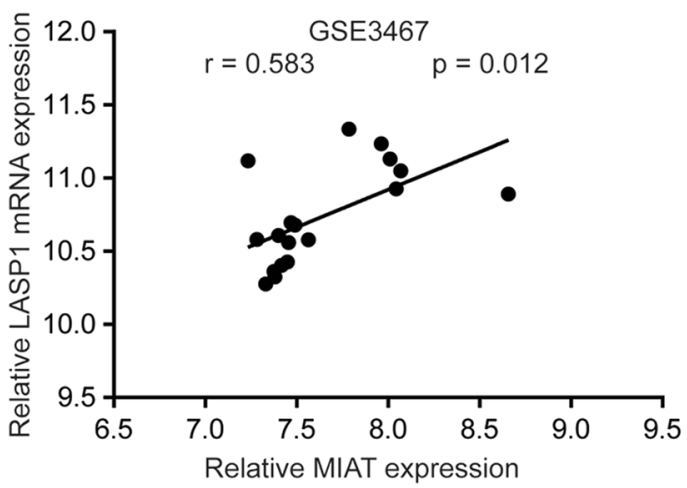

C

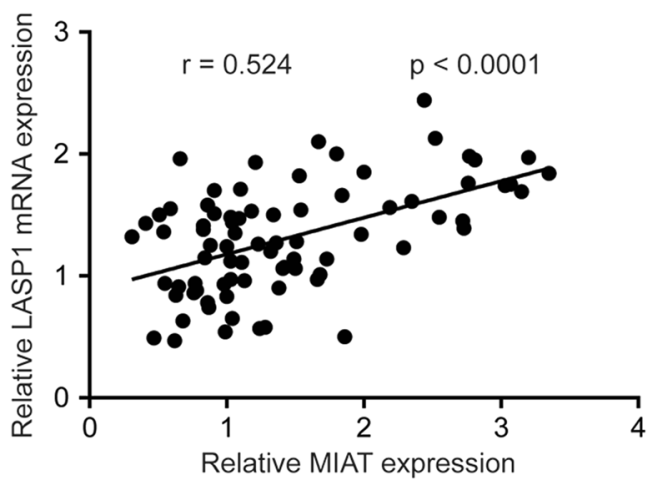

b

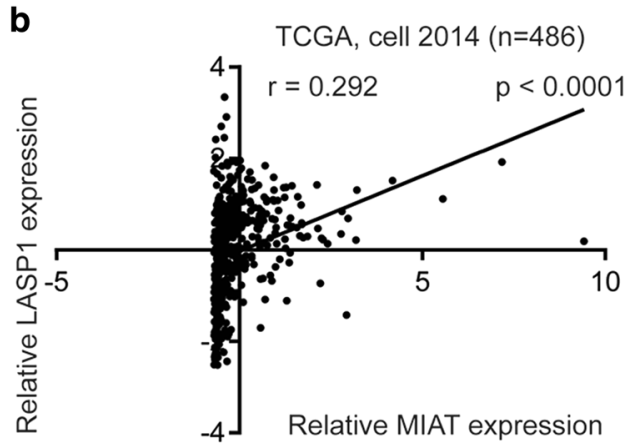

Fig. 7 MIAT expression is correlated with LASP1 mRNA levels in papillary thyroid cancer tissues. a Through analysis of expression data from 9 PTC tissues in GSE3467, a significant positive correlation between LASP1 mRNA levels and MIAT levels was observed in tumors and normal tissues from 9 patients with PTC. $\mathbf{b}$ Via analysis of TCGA dataset (cell, 2014), a significant positive correlation between LASP1 mRNA levels and MIAT levels was observed in tumors from 486 patients with PTC. c A significant positive correlation between LASP1 mRNA levels and MIAT levels was observed from 40 PTC tissues we collected

which contributed to overexpression of LASP1 [43]. We found that there was a putative binding site on LASP1 3'UTR for miR-324-3p. Further experiments validated that LASP1 was a direct target gene of miR-324-3p. This suggested a regulatory association among MIAT, miR324-3p and LASP1. Indeed, silencing of MIAT decreased LASP1 expression in PTC cells. More importantly, analysis of PTC expression dataset on public database and PTC tissues we collected indicated that there was a positive correlation between MIAT and LASP1 expression. LASP1 was proved to be regulated by several lncRNAs (PVT1, AFAP1-AS1) [44, 45], our study further identified MIAT as a new regulator of LASP1, at least in PTC cells. In the functional assays, overexpression of LASP1 recovered MIAT silencing induced cell proliferation, invasion and cycle inhibition, suggested that MIAT relied on regulation of LASP1 to regulate PTV cancer progression. Thus, a MIAT/miR-324-3p/LASP1 axis was discovered as a driver of PTC progression.

\section{Conclusion}

In conclusion, our data identified lncRNA MIAT as a key lncRNA in promoting the pathogenesis of PTC. MIAT might be used as potential biomarker or therapeutic target in the future, and should be the focus of future studies into the molecular mechanism of PTC.

\section{Additional file}

Additional file 1: Figure S1. Analysis of COLCA1, TNRC6C-AS1 and FAM30A expression in normal and tumor tissues from patients with PTC. A. Bioinformatic analysis of GSE3467 dataset revealed that there was no significant difference between COLCA1 expression in papillary thyroid cancer compared with normal tissues from 9 patients. B. Bioinformatic analysis of GSE3467 dataset revealed that TNRC6C-AS1 was overexpressed in papillary thyroid cancer compared with normal tissues from 9 patients. C. Bioinformatic analysis of GSE3467 dataset revealed that there was no significant difference between FAM30A expression in papillary thyroid cancer compared with normal tissues from 9 patients. 


\section{Acknowledgements \\ None.}

\section{Authors' contributions}

Clinical sample collection: ZW, CW, WL. Study design: ZW, ZA. Data acquisition and analysis: ZW, CW, WL. Manuscript preparation, editing and review: ZW, ZA. All authors read and approved the final manuscript.

\section{Funding}

This work was supported by the National Natural Science Foundation of China (81272722), Program for key talents of Zhongshan hospital (2015ZSYXGG12).

\section{Availability of data and materials}

They are available under special request.

\section{Ethics approval and consent to participate}

All patients provided written informed consent and the Ethic Committee of Fudan University approved the present study.

\section{Consent for publication}

All patients provided written informed consent to participate the study and agreed to publish data presented in the paper.

\section{Competing interests}

The authors declare that they have no competing interests.

Received: 4 January 2019 Accepted: 16 July 2019

Published online: 25 July 2019

\section{References}

1. Torre LA, Bray F, Siegel RL, Ferlay J, Lortet-Tieulent J, Jemal A. Global cancer statistics, 2012. CA Cancer J Clin. 2015;65(2):87-108.

2. Sipos JA, Mazzaferri EL. Thyroid cancer epidemiology and prognostic variables. Clin Oncol. 2010;22(6):395-404.

3. Sherman SI, Brierley JD, Sperling M, Ain KB, Bigos ST, Cooper DS, Haugen BR, Ho M, Klein I, Ladenson PW, et al. Prospective multicenter study of thyroid carcinoma treatment: initial analysis of staging and outcome. National Thyroid Cancer Treatment Cooperative Study Registry Group. Cancer. 1998;83(5):1012-21.

4. Shoup M, Stojadinovic A, Nissan A, Ghossein RA, Freedman S, Brennan MF, Shah JP, Shaha AR. Prognostic indicators of outcomes in patients with distant metastases from differentiated thyroid carcinoma. J Am Coll Surg. 2003;197(2):191-7.

5. Yoon JH, Kim J, Gorospe M. Long noncoding RNA turnover. Biochimie. 2015;117:15-21.

6. Alvarez-Dominguez JR, Hu W, Gromatzky AA, Lodish HF. Long noncoding RNAs during normal and malignant hematopoiesis. Int J Hematol. 2014;99(5):531-41.

7. Aune TM, Spurlock CF 3rd. Long non-coding RNAs in innate and adaptive immunity. Virus Res. 2016;212:146-60.

8. Batista PJ, Chang HY. Long noncoding RNAs: cellular address codes in development and disease. Cell. 2013;152(6):1298-307.

9. Bhan A, Mandal SS. Long noncoding RNAs: emerging stars in gene regulation, epigenetics and human disease. ChemMedChem. 2014:9(9):1932-56.

10. Xiang JF, Yin QF, Chen T, Zhang Y, Zhang XO, Wu Z, Zhang S, Wang HB, Ge J, Lu X, et al. Human colorectal cancer-specific CCAT1-L IncRNA regulates long-range chromatin interactions at the MYC locus. Cell Res. 2014;24(5):513-31.

11. Guo J, Hao C, Wang C, Li L. Long noncoding RNA PVT1 modulates hepatocellular carcinoma cell proliferation and apoptosis by recruiting EZH2. Cancer Cell Int. 2018;18:98.

12. Murugan AK, Munirajan AK, Alzahrani AS. Long noncoding RNAs: emerging players in thyroid cancer pathogenesis. Endocr Relat Cancer. 2018;25(2):R59-82.

13. Zhao JJ, Hao S, Wang LL, Hu CY, Zhang S, Guo LJ, Zhang G, Gao B, Jiang $Y$, Tian WG, et al. Long non-coding RNA ANRIL promotes the invasion and metastasis of thyroid cancer cells through TGF-beta/Smad signaling pathway. Oncotarget. 2016;7(36):57903-18.

14. Ishii N, Ozaki K, Sato H, Mizuno H, Saito S, Takahashi A, Miyamoto Y, Ikegawa S, Kamatani N, Hori M, et al. Identification of a novel non-coding RNA, MIAT, that confers risk of myocardial infarction. J Hum Genet. 2006;51(12):1087-99.

15. Crea F, Venalainen E, Ci X, Cheng H, Pikor L, Parolia A, Xue H, Nur Saidy NR, Lin D, Lam W, et al. The role of epigenetics and long noncoding RNA MIAT in neuroendocrine prostate cancer. Epigenomics. 2016;8(5):721-31.

16. Li Y, Jiang B, Wu X, Huang Q, Chen W, Zhu H, Qu X, Xie L, Ma X, Huang $G$. Long non-coding RNA MIAT is estrogen-responsive and promotes estrogen-induced proliferation in ER-positive breast cancer cells. Biochem Biophys Res Commun. 2018;503(1):45-50.

17. Sattari A, Siddiqui H, Moshiri F, Ngankeu A, Nakamura T, Kipps TJ, Croce CM. Upregulation of long noncoding RNA MIAT in aggressive form of chronic lymphocytic leukemias. Oncotarget. 2016;7(34):54174-82.

18. Luan T, Zhang X, Wang S, Song Y, Zhou S, Lin J, An W, Yuan W, Yang Y, Cai $H$, et al. Long non-coding RNA MIAT promotes breast cancer progression and functions as ceRNA to regulate DUSP7 expression by sponging miR155-5p. Oncotarget. 2017:8(44):76153-64.

19. Tomasetto C, Moog-Lutz C, Regnier CH, Schreiber V, Basset P, Rio MC. Lasp-1 (MLN 50) defines a new LIM protein subfamily characterized by the association of LIM and SH3 domains. FEBS Lett. 1995;373(3):245-9.

20. Chew CS, Chen X, Parente JA Jr, Tarrer S, Okamoto C, Qin HY. Lasp-1 binds to non-muscle F-actin in vitro and is localized within multiple sites of dynamic actin assembly in vivo. J Cell Sci. 2002;115(Pt 24):4787-99.

21. Chew CS, Parente JA Jr, Chen X, Chaponnier C, Cameron RS. The LIM and SH3 domain-containing protein, lasp-1, may link the CAMP signaling pathway with dynamic membrane restructuring activities in ion transporting epithelia. J Cell Sci. 2000;113(Pt 11):2035-45.

22. Orth MF, Cazes A, Butt E, Grunewald TG. An update on the LIM and SH3 domain protein 1 (LASP1): a versatile structural, signaling, and biomarker protein. Oncotarget. 2015;6(1):26-42.

23. Grunewald TG, Butt E. The LIM and SH3 domain protein family: structural proteins or signal transducers or both? Mol Cancer. 2008;7:31.

24. Gao W, Han J. Silencing of LIM and SH3 Protein 1 (LASP-1) inhibits thyroid cancer cell proliferation and invasion. Oncol Res. 2017;25(6):879-86.

25. Li B, Dewey CN. RSEM: accurate transcript quantification from RNA-Seq data with or without a reference genome. BMC Bioinform. 2011;12:323.

26. Gao J, Aksoy BA, Dogrusoz U, Dresdner G, Gross B, Sumer SO, Sun Y, Jacobsen A, Sinha R, Larsson E, et al. Integrative analysis of complex cancer genomics and clinical profiles using the cBioPortal. Sci Signal. 2013;6(269):pl1.

27. Livak KJ, Schmittgen TD. Analysis of relative gene expression data using real-time quantitative PCR and the $2(-\triangle \triangle C(T))$ method. Methods. 2001;25(4):402-8

28. Hou S, Lin Q, Guan F, Lin C. LnCRNA TNRC6C-AS1 regulates UNC5B in thyroid cancer to influence cell proliferation, migration, and invasion as a competing endogenous RNA of miR-129-5p. J Cell Biochem. 2018;119(10):8304-16.

29. Liu Y, Li J, Li F, Li M, Shao Y, Wu L. SNHG15 functions as a tumor suppressor in thyroid cancer. J Cell Biochem. 2019;120(4):6120-6.

30. Liu Z, Yan Y, Cao S, Chen Y. Long non-coding RNA SNHG14 contributes to gastric cancer development through targeting miR-145/SOX9 axis. J Cell Biochem. 2018;119(8):6905-13.

31. Cui HX, Zhang MY, Liu K, Liu J, Zhang ZL, Fu L. LncRNA SNHG15 promotes proliferation and migration of lung cancer via targeting microRNA211-3p. Eur Rev Med Pharmacol Sci. 2018;22(20):6838-44.

32. Gu J, Zhang X, Miao R, Ma X, Xiang X, Fu Y, Liu C, Niu W, Qu K. A threelong non-coding RNA-expression-based risk score system can better predict both overall and recurrence-free survival in patients with small hepatocellular carcinoma. Aging. 2018;10(7):1627-39.

33. Muhanhali D, Zhai T, Jiang J, Ai Z, Zhu W, Ling Y. Long non-coding antisense RNA TNRC6C-AS1 is activated in papillary thyroid cancer and promotes cancer progression by suppressing TNRC6C expression. Front Endocrinol. 2018:9:360

34. Gong J, Jin S, Pan X, Wang G, Ye L, Tao H, Wen H, Liu Y, Xie Q. Identification of long non-coding RNAs for predicting prognosis among patients with thymoma. Clin Lab. 2018;64(7):1193-8. 
35. Qu Y, Xiao H, Xiao W, Xiong Z, Hu W, Gao Y, Ru Z, Wang C, Bao L, Wang K, et al. Upregulation of MIAT regulates LOXL2 expression by competitively binding MiR-29c in clear cell renal cell carcinoma. Cell Physiol Biochem. 2018;48(3):1075-87.

36. Ebert MS, Neilson JR, Sharp PA. MicroRNA sponges: competitive inhibitors of small RNAs in mammalian cells. Nat Methods. 2007;4(9):721-6.

37. Sun $C$, Huang L, Li Z, Leng $K$, Xu Y, Jiang X, Cui Y. Long non-coding RNA MIAT in development and disease: a new player in an old game. J Biomed Sci. 2018;25(1):23

38. Liu Z, Wang H, Cai H, Hong Y, Li Y, Su D, Fan Z. Long non-coding RNA MIAT promotes growth and metastasis of colorectal cancer cells through regulation of miR-132/Derlin-1 pathway. Cancer Cell Int. 2018;18:59.

39. Liu C, Li G, Yang N, Su Z, Zhang S, Deng T, Ren S, Lu S, Tian Y, Liu Y, et al. miR-324-3p suppresses migration and invasion by targeting WNT2B in nasopharyngeal carcinoma. Cancer Cell Int. 2017;17:2.

40. Kuo WT, Yu SY, Li SC, Lam HC, Chang HT, Chen WS, Yeh CY, Hung SF, Liu TC, Wu T, et al. MicroRNA-324 in human cancer: miR-324-5p and miR324-3p have distinct biological functions in human cancer. Anticancer Res. 2016;36(10):5189-96.

41. Jiang $N$, Jiang $X$, Chen Z, Song $X$, Wu L, Zong D, Song D, Yin L, Wang D, Chen C, et al. MiR-203a-3p suppresses cell proliferation and metastasis through inhibiting LASP1 in nasopharyngeal carcinoma. J Exp Clin Cancer Res. 2017;36(1):138.
42. Nishikawa R, Goto Y, Sakamoto S, Chiyomaru T, Enokida H, Kojima S, Kinoshita T, Yamamoto N, Nakagawa M, Naya Y, et al. Tumor-suppressive microRNA-218 inhibits cancer cell migration and invasion via targeting of LASP1 in prostate cancer. Cancer Sci. 2014;105(7):802-11.

43. Li H, Liu G, Pan K, Miao X, Xie Y. Methylation-induced downregulation and tumor suppressive role of microRNA-29b in gastric cancer through targeting LASP1. Oncotarget. 2017;8(56):95880-95.

44. Lian Y, Xiong F, Yang L, Bo H, Gong Z, Wang Y, Wei F, Tang Y, Li X, Liao Q, et al. Long noncoding RNA AFAP1-AS1 acts as a competing endogenous RNA of miR-423-5p to facilitate nasopharyngeal carcinoma metastasis through regulating the Rho/Rac pathway. J Exp Clin Cancer Res. 2018;37(1):253

45. Li PD, Hu JL, Ma C, Ma H, Yao J, Chen LL, Chen J, Cheng TT, Yang KY, Wu G, et al. Upregulation of the long non-coding RNA PVT1 promotes esophageal squamous cell carcinoma progression by acting as a molecular sponge of miR-203 and LASP1. Oncotarget. 2017;8(21):34164-76.

\section{Publisher's Note}

Springer Nature remains neutral with regard to jurisdictional claims in published maps and institutional affiliations.
Ready to submit your research? Choose BMC and benefit from:

- fast, convenient online submission

- thorough peer review by experienced researchers in your field

- rapid publication on acceptance

- support for research data, including large and complex data types

- gold Open Access which fosters wider collaboration and increased citations

- maximum visibility for your research: over $100 \mathrm{M}$ website views per year

At BMC, research is always in progress.

Learn more biomedcentral.com/submissions 